\title{
The possibility of deeper or shallower extent of the source area of Nankai Trough earthquakes based on the 1707 Hoei tsunami heights along the Pacific and Seto Inland Sea coasts, southwest Japan
}

\author{
Mamoru Hyodo ${ }^{1 *}$, Takane Hori ${ }^{1}$, Kazuto Ando ${ }^{2}$ and Toshitaka Baba ${ }^{1}$
}

\begin{abstract}
To validate the abundance of scenarios of large earthquakes in the Nankai Trough, we examined the effects of both lateral and vertical expansions of the source areas on maximum tsunami heights along the Pacific coast and Seto Inland Sea. The recently proposed Nankai Trough earthquake scenario $\left(M_{w}=9\right)$ has a maximum slip of $20 \mathrm{~m}$ near the trough axis. However, the predicted tsunami heights exceeded those obtained from historical records of damage caused by the 1707 Hoei tsunami event at Tosa Bay and along the Pacific coastlines near the Kii Channel, owing to the large slip on the up-dip extension of fault segments off Shikoku Island. Such discrepancy indicates that for segments off Shikoku Island, the slip near the trough axis was unremarkable, even for the 1707 Hoei earthquake event, which is considered one of the larger historical Nankai Trough earthquake events. For segments east of the Kii Peninsula, the large slip on the up-dip end might be ineffective. While the proposed $M_{w}$ 9-class scenario also includes large slip of several meters on the down-dip side (down to about 35-km depth), coseismic crustal subsidence reached further landward than is usual for Nankai Trough earthquakes. For the Seto Inland Sea region, this resulted in maximum subsidence of about $1 \mathrm{~m}$, and such crustal subsidence effectively increased the height of the tsunamis. Furthermore, simulated tsunami heights, corrected for crustal subsidence, were in good agreement with those obtained from historical records of the damage caused in the Seto Inland Sea region.
\end{abstract}

Keywords: Nankai Trough earthquake; Historical tsunami; Earthquake scenario

\section{Background}

Along the Pacific coast of southwestern Japan, great earthquakes have occurred intermittently with recurrence intervals of 90 to 200 years due to the subduction of the Philippine Sea plate along the Nankai Trough (Figure 1). Hereafter, these great earthquakes will be referred to as Nankai Trough earthquakes. The last two Nankai Trough earthquakes occurred in 1944 (Showa Tonankai earthquake) and 1946 (Showa Nankai earthquake), as indicated at the bottom of Figure 1. About 70 years have passed

\footnotetext{
* Correspondence: hyodo@jamstec.go.jp

'Research and Development Center for Earthquake and Tsunami (CEAT), Japan Agency for Marine-Earth Science and Technology (JAMSTEC), 3173-25 Showa-machi, Kanagawa-ku, Yokohama, Kanagawa 236-0001, Japan Full list of author information is available at the end of the article
}

since the occurrence of these earthquakes, which is about half the average recurrence interval of a Nankai Trough earthquake; hence, it is now an appropriate time to implement measures against the next great earthquake.

For several decades, it has been believed that large seismogenic and/or tsunamigenic slip does not occur on shallower parts of the plate interface near the trough axis, although splay faults might cause large tsunamis (Fukao 1979; Park and Kodaira 2012). Furthermore, it has been suggested that the magnitude of Nankai Trough earthquakes is controlled mainly by the number of fault segments that rupture concurrently at seismogenic depth (Ishibashi 2004). Thus, it has been believed that Nankai Trough earthquakes occur in various patterns with laterally arranged rupture units called segments (see Figure 1). In 


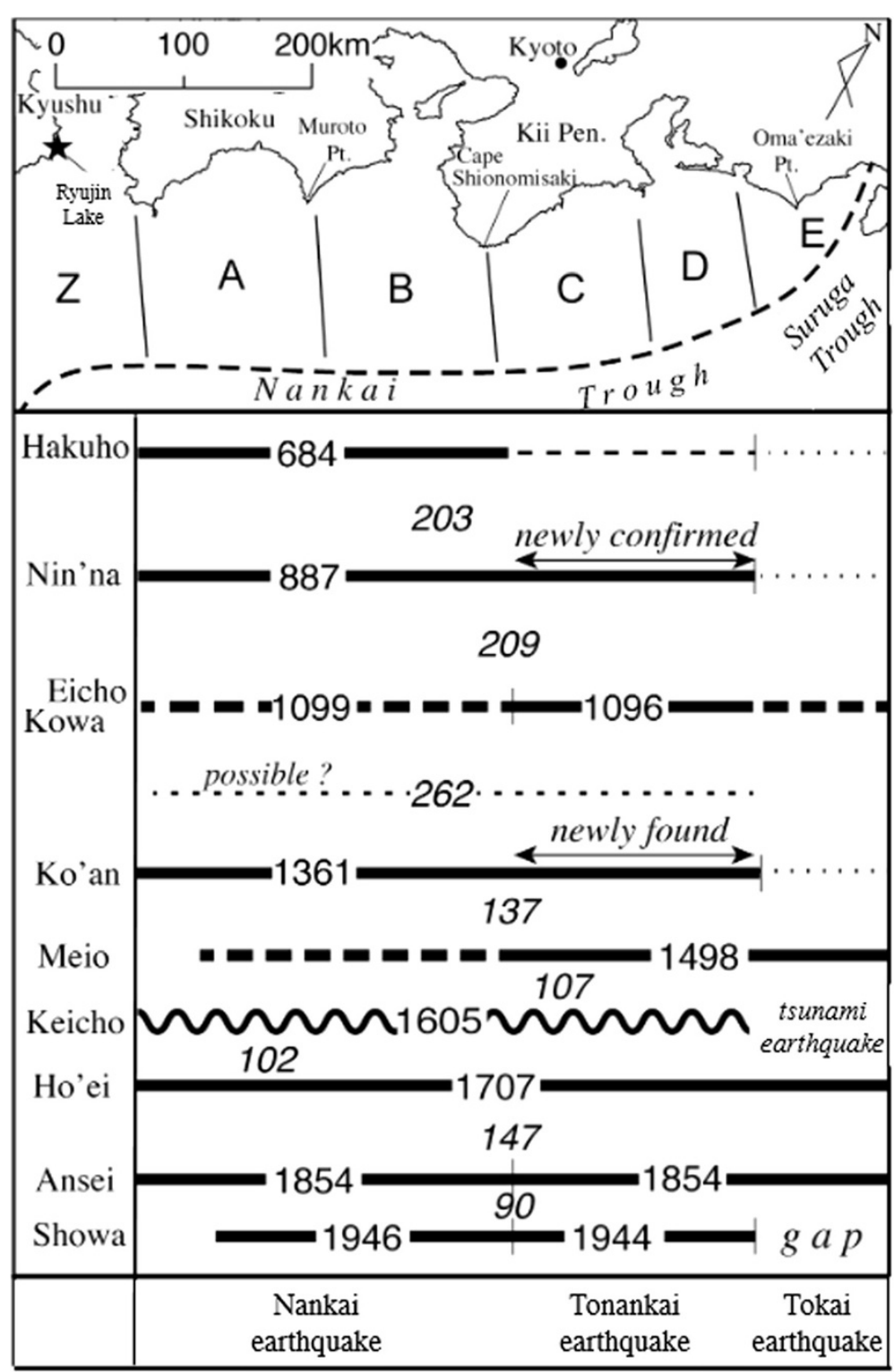

Figure 1 Sequence of historical Nankai Trough earthquake events. The map shows the distribution of rupture segments of Nankai Trough earthquakes. Each rupture segment has been broken or unbroken in historical Nankai Trough earthquakes. In the chronological diagram below, horizontal thick lines indicate ruptured segments in each historical event, named after the corresponding Japanese era (shown in the left column). The thick dashed and thin dotted lines indicate segments that are probably and possibly broken, respectively.

smaller Nankai events, western (A and B) and eastern segments $(\mathrm{C}, \mathrm{D}$, and $\mathrm{E})$ tend not to rupture concurrently, but with temporal separation (from $30 \mathrm{~h}$ to 2 years), and/or seismic ruptures do not always reach segments $\mathrm{A}$ and $\mathrm{E}$, which are located at the western and eastern edges of the Nankai Suruga Trough, respectively. Conversely, in larger Nankai events (e.g., the 1707 Hoei earthquake and tsunami events), segments $\mathrm{A}$ to $\mathrm{E}$ tend to rupture in a nearconcurrent way, and even the additional rupture of the westward extension (i.e., segment $\mathrm{Z}$ in Figure 1) has been suggested to be concurrent with ruptures of segments $A$ to E (Furumura et al. 2011). Accordingly, the recurrence of a
Nankai Trough earthquake has been understood - and anticipated - within the traditional viewpoint of the concurrent rupture of lateral fault segments.

The disastrous Tohoku earthquake of 2011 in northeastern Japan, however, was accompanied by massive tsunamis due to large slip (approximately $50 \mathrm{~m}$ ) near the Japan Trench (Fujiwara et al. 2011). This indicates that for other subduction zones, we cannot exclude the possibility of seismic events located at the shallowest parts of subduction plate interfaces. Actually, in the Nankai Trough region, seismic slip on the shallowest part of the decollement was confirmed by evidence from a core drilled near 
the Nankai Trough off Kumano basin (Sakaguchi et al. 2011). Furthermore, based on the movement of coastal rocks at the southern tip of the Kii Peninsula, Namegaya et al. (2011) guessed that tsunamis, considerably larger than those usually found in the Nankai Trough region, occur at that location. Therefore, the assessment of the damage that could result from the recurrence of a Nankai Trough earthquake in the near future was reconsidered by including the possible slip on the up-dip extension. Moreover, the different possible strong ground motions and tsunamis predicted by maximum-class earthquake scenarios with large slip ( 40 to $50 \mathrm{~m}$ ) on shallow subduction interfaces - similar to the Tohoku earthquake of 2011 - have been published in an official report (Cabinet Office 2012). Based on the previous Nankai Trough earthquake scenarios (Central Disaster Prevention Council 2003), the source area used in the scenarios in the 2012 report was extended laterally westward to include the southern tip of the Kyushu region. Furthermore, the vertical range of the source area was also extended - from the usual seismogenic zone - to include both up-dip and down-dip extensions. The up-dip extension reaches the Nankai Trough axis, while the downdip limit is shifted to the depth of slow slip events. For the extended source area, maximum slips of 40 to $50 \mathrm{~m}$ on the up-dip side of the seismogenic zone were kinematically assigned, in an additional slip of several tens of meters at both seismogenic and down-dip depths (Cabinet Office 2012). Consequently, the magnitudes of Nankai Trough earthquakes become $M_{w}>9.1$ in the revised scenarios. Therefore, the estimated resultant tsunami damage could increase locally by several times compared with that estimated in previous scenarios with large slip at the usual seismogenic depth (Cabinet Office 2012).

As mentioned above, there is the possibility that the source area of Nankai Trough earthquakes extends to deeper or shallower extent. Here, we examine whether scenarios with up-dip or down-dip extensions of the source area are consistent with historical Nankai Trough earthquakes, by focusing particularly on consistency with the 1707 Hoei earthquake. In Japan, there exist many historical documents dating back to the 1600s, not only regarding the capital but also various other parts of the country. Thus, historical descriptions of damage by earthquakes or tsunamis are more reliable than for previous eras. Because of the collection of such reliable descriptions or instrumental records for such events, the 1707 Hoei event is generally considered the largest of the four Nankai Trough earthquakes that have occurred since 1600 . Hence, we regard the Hoei event as representative of larger Nankai Trough earthquakes. For the earthquake scenarios, we used the physics-based Nankai Trough earthquake scenarios obtained from quasidynamic earthquake cycle simulations, as discussed in the following.
Thanks to the developments in the field of high-performance computing, simulations of large-scale earthquakegeneration cycles, based on the driving forces of relative plate motion and the fault-friction law, can be realized. For the Nankai Trough region, such physics-based simulations have been conducted to mimic real-world earthquake sequences and interpret the mechanisms underlying earthquake-generation cycles along the Nankai Trough (e.g., Hori et al. 2004; Hori 2006; Hyodo and Hori 2013). This has resulted in the accumulation of many earthquake scenarios with widely varying estimates of magnitude or occurrence pattern. However, these studies have been limited to discussions of qualitative comparisons of earthquake recurrences and/or slip distributions of simulated and historical earthquake sequences (e.g., Hori 2006).

Previously, kinematic sources, represented by a few rectangular fault planes, have been used for forward modeling of seismic waves or tsunamis to improve understanding of the rupture processes and the extent of historical earthquakes. However, owing to recent advances in physics-based forward modeling, improved and more realistic simulation-based earthquake scenarios have been accumulated, which might replace these kinematic scenarios as the dominant method of forward modeling of the source and rupture processes. A considerable advantage of these simulation-based scenarios is their ability to mimic real-world rupture processes in a realistic way, through unprecedented spatiotemporal smoothness of simulated ruptures. Thus, by comparing predicted tsunami heights obtained for each scenario with historical damage records from particular historical earthquake events, we can narrow down the number of scenarios potentially suitable for the prediction of tsunami heights generated by future Nankai Trough earthquake events.

To explore the available scenarios of Nankai Trough earthquakes for potentially suitable candidates, we simulated tsunami heights due to earthquake scenarios calculated by seismic-cycle simulations and checked for consistency between simulated tsunami heights and those obtained from historical damage records. In many previous studies, comparisons of simulated and historical damages primarily discussed the records of damage caused along the Pacific coast, extending from the Kyushu to Tokai regions (e.g., Furumura et al. 2011). However, for the 1707 Hoei earthquake event (considered one of the larger historical Nankai Trough earthquake events) or the 1854 Ansei Nankai earthquake, documentation suggested that severe tsunami damage, from a maximum tsunami height of about $3 \mathrm{~m}$, occurred in the Seto Inland Sea region, especially on the eastern side of the Seto Inland Sea. However, only limited damage from a tsunami of about $1 \mathrm{~m}$ in height, similar to a storm surge, was documented for smaller Nankai Trough earthquakes such as the 1946 Nankai earthquake 
(Hatori 1988; Kitahara et al. 2012). Figure 2 shows the damage around the Seto Inland Sea from the 1707 tsunami; damage inside the Inland Sea increases from west to east. As this feature is in common with the 1854 Ansei Nankai earthquake (Hatori 1988), the damage documented for the Seto Inland Sea region could be an important factor for the evaluation of the characteristics of larger historical Nankai Trough earthquake events. As a first step in validating the many Nankai Trough earthquake scenarios available, we focus on a simulation-based earthquake scenario (an earthquake scenario with maximum moment magnitude in Hyodo and Hori (2013)), of which the source area is comparable in size to that of the maximum-class kinematic earthquakes report published by Cabinet Office (2012). In that report, 11 kinematic scenarios are considered, each with a different distribution of the large local slip area of about 40 to $50 \mathrm{~m}$ along the Nankai Trough axis. The earthquake scenarios in Hyodo and Hori (2013) are based on physics-based earthquake simulations with realistic plate velocity (approximately $6.5 \mathrm{~cm} /$ year) and the velocityweakening region from the integrated information of possible seismic slip distribution from past Nankai Trough earthquakes. In the resultant seismic cycles, two alternative earthquakes recur about every 170 to 200 years, which is nearly equal to the maximum interval of historical Nankai Trough earthquakes. The larger-earthquake scenario in Hyodo and Hori (2013) occurs once every two seismic cycles and has the largest slip area of about $20 \mathrm{~m}$ near the Nankai Trough axis, extending from the western edge of Shikoku to west of the Kii Peninsula. Accordingly, the difference of moment magnitudes between the scenarios $\left(M_{w}>9.1\right)$ of Cabinet Office (2012) and the largerearthquake scenario $\left(\mathrm{M}_{\mathrm{w}}=9.0\right)$ of Hyodo and Hori (2013) is caused mainly by the difference of the slip amount near the up-dip end of the plate interface. The tsunami heights from the larger-earthquake scenario of Hyodo and Hori
(2013) were compared with those obtained from historical damage records from the 1707 Hoei tsunami event for the Pacific and Seto Inland Sea regions to evaluate the degree to which the physics-based $\mathrm{M}_{\mathrm{w}}$ 9-class scenario is consistent with the 1707 Hoei earthquake, the historical larger Nankai Trough earthquake event.

\section{Historical tsunami damage}

Here, we briefly introduce the 1707 Hoei tsunami damage that will be compared with the simulated tsunami heights in this study. Many previous studies have collated data on historical tsunami heights in southwestern Japan based on records of damage (e.g., Hatori 1974, 1985; Murakami et al. 1996). Hatori (1974) compiled pre-existing tsunami height lists of historical Nankai Trough earthquakes, and Hatori (1985) and Murakami et al. (1996) collected descriptions of historical tsunamis from unconfirmed old documents in Kyushu and Shikoku districts, respectively. Then, based on definite descriptions on tsunami heights, such as inundation up to the floorboards at a particular place, site elevations were measured through leveling surveys in field investigations; thus, the inundation height was re-affirmed for each description. From the results of above three studies, we extracted the 1707 Hoei tsunami-height data on the Pacific and Seto Inland Sea coasts and compared them with the simulated tsunami heights.

\section{Methods}

Hyodo and Hori (2013) proposed a model of $\mathrm{M}_{\mathrm{w}}$ 9-class Nankai Trough earthquakes based on quasi-dynamic earthquake-cycle simulations. In their simulated earthquake sequence, the $M_{\mathrm{w}}$ 9-class Nankai Trough earthquake and a smaller one occurred alternately. In Hyodo and Hori (2013), the slip distributions of simulationbased earthquakes are defined through the selection of a

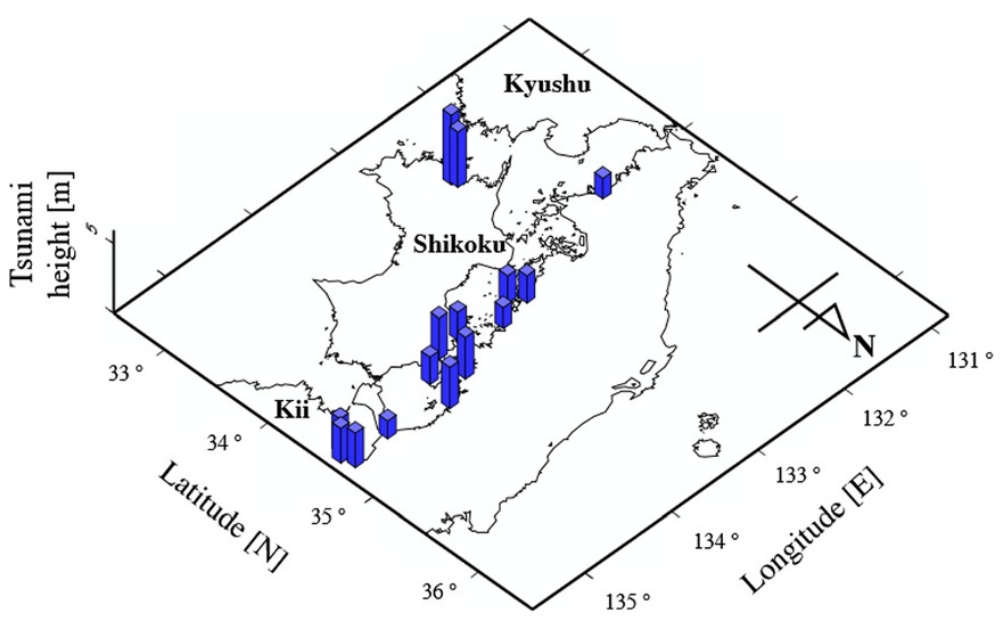

Figure 2 Tsunami heights of the 1707 Hoei tsunami event in the Seto Inland Sea region. 
slip-velocity threshold of $V>1 \mathrm{~cm} / \mathrm{s}$, and the inclusion of slip above this threshold in the distribution during unstable slip events. Such 'velocity-based' slip distributions might depend on the choice of the threshold value. Hence, for the initial conditions of tsunami simulations in this paper, we adopt another slip distribution, defined by selecting a specific period during which all slip is included in the distribution. Thus, if we select the specific period of $1,000 \mathrm{~s}$ for the 'duration-based' slip distribution, the total amount of fault slip from the onset of the unstable slip to $1,000 \mathrm{~s}$ afterwards is extracted from the simulation result as the initial condition of the tsunami calculation.

Evidently, uncertainty could also be introduced into the duration-based slip distribution through the selection of this time interval. However, to some extent, the slip distribution must become smooth if the time interval is longer because spatiotemporal propagation of slip is equal to that of the raw simulation result during the selected time interval. Actually, we confirmed that slip distribution is smooth and not largely dependent on the value of the selected time interval, if a time interval of between several hundreds to $1,000 \mathrm{~s}$ is selected. However, for the velocity-based slip distribution, spatiotemporal smoothness might not be guaranteed because the resultant slip distribution might have unphysical gaps, depending on the value of the slip-velocity threshold.

Fortunately, there are no significant differences between a velocity-based slip distribution with a slip-velocity threshold of $1 \mathrm{~cm} / \mathrm{s}$ and a duration-based slip distribution with a time interval of $1,000 \mathrm{~s}$. For the $\mathrm{M}_{\mathrm{w}} 9$-class Nankai Trough earthquake scenario of Hyodo and Hori (2013), the estimated moment magnitudes were $\mathrm{M}_{\mathrm{w}}=8.97$ in Hyodo and Hori (2013) and $\mathrm{M}_{\mathrm{w}}=9.03$ in this study. Here, we assumed a rigidity of $30 \mathrm{GPa}$ in evaluating the moment magnitudes. In both distributions of slip, large slips (i.e., $>10 \mathrm{~m}$ ) were distributed on the shallow (0 to $25-\mathrm{km}$ depth) plate interface along the Nankai Trough off the eastern Kyushu and Tokai regions, as shown in Figure 3a. The maximum slip reached $20 \mathrm{~m}$ near the Nankai Trough axis off the Shikoku region. Toward the down-dip direction, a slip of several meters extended to a depth of more than $30 \mathrm{~km}$. Hereafter, the earthquake scenario with $M_{w}=9.03$ will be referred to as the larger-earthquake scenario. Conversely, for the other earthquake scenario that appeared as a pair of the $\mathrm{M}_{\mathrm{w}} 9$-class scenarios in Hyodo and Hori (2013), a maximum slip of about $9 \mathrm{~m}$ was distributed along the seismogenic depth (10 to $30 \mathrm{~km})$ off the northern Kyushu and Tokai regions, as shown in Figure 3b. Furthermore, the difference in slip distributions was found to be small: $\mathrm{M}_{\mathrm{w}}=8.58$ and $\mathrm{M}_{\mathrm{w}}=8.66$ in Hyodo and Hori (2013) and in this study, respectively. In evaluating moment magnitudes, the same rigidity $(30 \mathrm{GPa})$ as in larger-earthquake scenario was assumed. The earthquake scenario with $\mathrm{M}_{\mathrm{w}}=8.66$ will be referred to as the smallerearthquake scenario in the following.

To examine the possibility of the deeper or shallower extent of the source areas in Nankai Trough earthquakes, we compared tsunami heights predicted in the scenario with $M_{w}=9.03$ to real damage caused by the 1707 Hoei earthquake event, i.e., we evaluated the degree to which the newly proposed $\mathrm{M}_{\mathrm{w}}$ 9-class Nankai Trough earthquake scenario was consistent with reality. For the comparison of predicted and real damages, we considered damaged sites, not only along the Pacific coastline but also in the Seto Inland Sea region.

\section{JAGURS code for tsunami simulation}

To compute the predicted tsunami heights based on simulated-earthquake scenarios, 9-h tsunami simulations were performed using the recently developed parallel finitedifference tsunami simulation code JAGURS (Baba et al. 2014), which solves nonlinear shallow-water equations numerically using the initial submarine deformation resulting from earthquake scenarios. To assess tsunamis resulting from Nankai Trough earthquakes, 9-h simulations are (a) Larger-earthquake scenario $\left(M_{w}=9.03\right)$

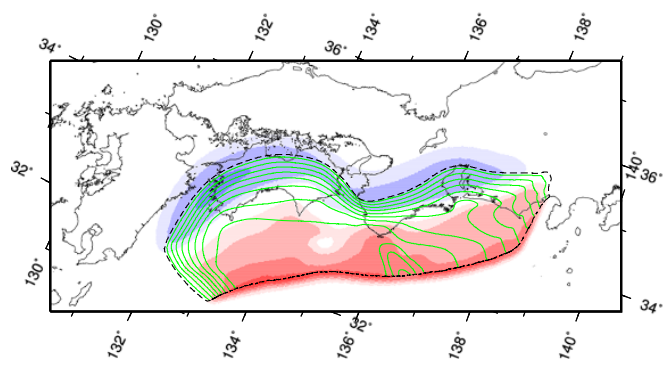

\section{(b) Smaller-earthquake scenario $\left(M_{w}=8.66\right)$}

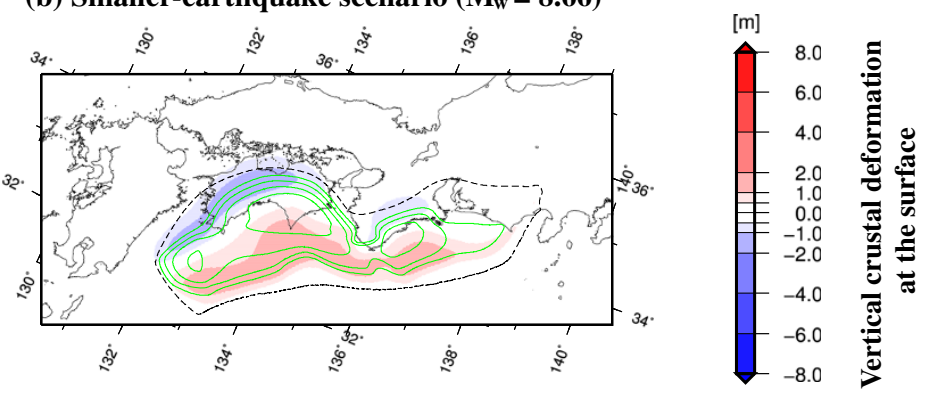

Figure 3 Slip distributions and resultant vertical deformations for the larger- and smaller-earthquake scenarios. In each panel, the assumed slip distribution is represented by green contour lines with intervals of $2 \mathrm{~m}$; blue and red regions correspond to subsidence and uplift, respectively. As a reference, the region with slip of $>1 \mathrm{~m}$ in the larger-earthquake scenario is bounded by the broken black line: (a) larger-earthquake scenario and (b) smaller-earthquake scenario. 
sufficiently long to evaluate the maximum heights of tsunamis at target regions because tsunamis reach the Pacific coast and the Seto Inland Sea region within about $30 \mathrm{~min}$ and $4 \mathrm{~h}$, respectively, after the occurrence of Nankai Trough earthquakes.

\section{Computational domain and grid spacing}

The entire computational domain of the tsunami simulation is shown as a black rectangle with dimensions of $11^{\circ}$ (longitude: 130 to $141^{\circ} \mathrm{E}$ ) $\times 6.85^{\circ}$ (latitude: 29 to $35.85^{\circ} \mathrm{N}$ ) in Figure 4. A discretization - for numerical calculation of 2 arc sec was used for both latitudinal and longitudinal directions over the entire computational domain. Hence, discretization resulted in 19,801 longitudinal grid points and 12,331 latitudinal grid points, yielding a total of $19,801 \times 12,331=244,166,131$ grid points. The computational domain was provided with bathymetry by subsampling and interpolation of the M7000 map series provided by the Marine Information Research Center (MIRC) of the Japan Hydrographic Association (JHA), using intervals of 2 arc sec for tsunami computations. The M7000 series is a set of digital bathymetric contours constructed by combining the basic map of the coastal waters of Japan with other sources of bathymetric information.

\section{Sources and initial conditions}

For the duration-based coseismic slip distributions, we were able to calculate the corresponding surface vertical deformation using the slip response in the homogeneous elastic half-space. The source area of the larger earthquake of Hyodo and Hori (2013) was extrapolated from previous estimates of Nankai Trough earthquakes in the

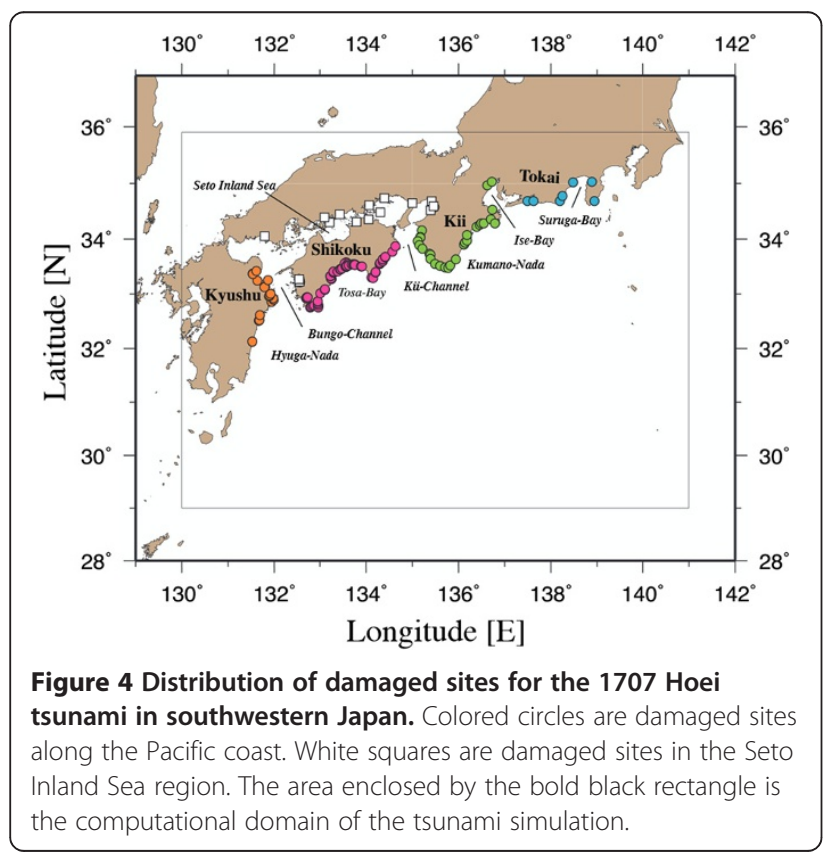

westward and up- and down-dip directions, similar to the maximum-class model of Cabinet Office (2012).

As mentioned in the introduction, it is important to understand how such extrapolations of source extensions affect tsunami heights at the Pacific coast and in the Seto Inland Sea region. Accordingly, we divided the larger-earthquake scenario into several sub-regions and computed the corresponding crustal vertical deformations. Then, for each crustal deformation, due to the slip of a sub-region or group of several sub-regions, we compared the simulated tsunami heights with those obtained from historical damage records from the 1707 Hoei tsunami event.

Because we were interested primarily in examining the effects of upper and lower extensions of the source area on coastal tsunami heights, we assumed that the up-dip and down-dip limits of the sub-regions were bounded along iso-depth contours in order to divide the slip distribution of the larger-earthquake scenario into subregions. Slip distributions at the edges of the sub-regions were linearly tapered by filters, as shown in Figure 5, to avoid unrealistic slip with sharp stepwise distributions. In Figure 6, the surface vertical deformations due to slips of three sub-slip regions are shown, corresponding to the considered earthquake scenarios. These surface deformations were used as initial conditions for the tsunami simulations. For reasons of simplification, the surface vertical deformations due to slips in Figure 3 and sub-slips in Figure 6 were assumed to form linearly within the initial $60 \mathrm{~s}$ of the tsunami simulation. However, the slip distributions shown in Figures 3 and 6 were formed during a period from the beginning of the earthquake to $1,000 \mathrm{~s}$ afterwards in the quasi-dynamic earthquake-cycle simulation (see 'Methods' section). This is because the inclusion of the rupture propagation is too complex to discuss the effect of the slip of each subregion on tsunami heights.

It should also be noted that the southwestern bound of large slip in the Hyuga-Nada region was moved to around $32^{\circ} \mathrm{N}$ for the three sub-slip distributions in Figure 6. This is because Furumura et al. (2011) confirmed that the southwestern extension of the source area around $32^{\circ} \mathrm{N}$ is necessary for the reproduction of tsunami heights observed during the 1707 Hoei tsunami event along the eastern coast of Kyushu Island. Therefore, in this study, we focused on the effects of up-dip and down-dip extensions of the source region on tsunami height along the Pacific coasts and in the Seto Inland Sea region.

\section{Results and discussion}

Throughout this study, in assessing simulated tsunami heights, we added the crustal vertical deformation - due to the various earthquake scenarios - to the calculated 


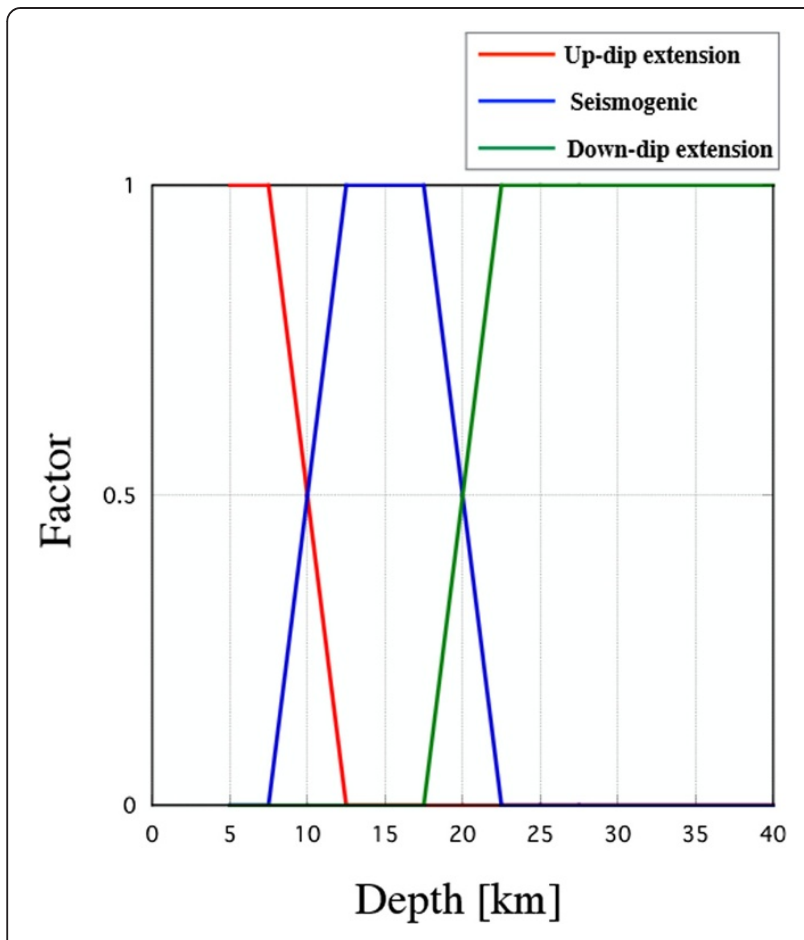

Figure 5 Depth distribution of filters used to divide slip distribution of larger-earthquake scenario into three sub-regions. It is assumed that the up-dip and down-dip ranges of sub-regions are bounded by iso-depth contours and that slip distributions at edges of sub-regions are linearly tapered by the filters shown in this figure.

tsunami height with respect to the level of seawater at rest. Thus, the coastal tsunami height was measured from the vertical position of the site that was moved by coseismic crustal deformation. Consequently, coastal subsidence due to coseismic crustal deformation increases tsunami height, whereas uplift acts to decrease coastal inundation.

\section{Tsunami heights along the Pacific coastline of Kyushu region}

First, we calculated the Pacific coastal tsunami heights from the two earthquake scenarios shown in Figure 3. The source area of the larger-earthquake scenario (Figure 3a) is comparable with that of the maximum-class Nankai Trough earthquake scenario of Cabinet Office (2012), although its magnitude $\left(M_{w}=9.03\right)$ is smaller $\left(M_{w}>9.1\right.$; Cabinet Office (2012)) because of the difference in the slip amount, especially at the up-dip end. However, the magnitude of the smaller-earthquake scenario $\left(\mathrm{M}_{\mathrm{w}}=8.66\right.$; Figure $3 \mathrm{~b}$ ) is nearly identical to that of the previous maximum-class scenario, i.e., $\mathrm{M}_{\mathrm{w}}=8.7$ (Central Disaster Prevention Council 2003).

In Figure $7 \mathrm{a}$, tsunami heights obtained from historical damage records from the 1707 Hoei tsunami event along the Pacific coast of the Kyushu region are plotted in orange, together with the maximum-height tsunami profiles resulting from the larger- and smaller-earthquake scenarios (plotted in black and gray, respectively). The maximumheight tsunami profile resulting from the larger-earthquake scenario is much higher than almost all those determined from historical damage records (Figure 7a). Conversely, the profiles resulting from sub-slip models 1, 2, and 3 (Figure 7b), assumed to have narrower source regions in the Hyuga-Nada region than the larger-earthquake scenario, all indicate nearly identical patterns to those obtained for the smaller-earthquake scenario (Figure 7a). Thus, the simulated tsunami heights due to the smaller-earthquake scenario and sub-slip models 1, 2, and 3 appear consistent with historical tsunami heights on the southern Pacific coast of Kyushu from Takanabe to Saiki, except for a few damaged sites. For northern damage sites along the Bungo Channel, the smaller-earthquake scenario and sub-slip model 3 are relatively consistent with historical tsunami heights.

To evaluate the consistency of the scenarios more quantitatively with data, we calculated $K$ and $\kappa$ values, as defined by Aida (1978). $K$ is calculated from $\log K=(1 /$ n) $\Sigma \log K_{i}$ as a geometric mean of $K_{i}$, where $K_{i}=x_{i} / y_{i}$, for which $x_{i}$ and $y_{i}$ are the observed and computed tsunami heights at the $i$ th damaged site, respectively, $n$ is the total number of damaged sites, and $\kappa$ represents the variation of $K_{i}$. The second and third columns of Table 1 contain the values of $K$ and $\kappa$ deduced from 20 damaged sites in the Kyushu district for five earthquake scenarios. As a scenario with a $K$-value neighboring one is considered more reliable, the smaller-earthquake scenario $(K=$ $0.99)$ and sub-slip model $3(K=1.01)$ are appropriate for reproducing the tsunami heights along the Pacific coast of the Kyushu region. These results indicate that historical damage records for the Pacific coast of the Kyushu region can be explained by the inclusion of the western extension of the Nankai Trough earthquake source area to the Hyuga-Nada region, as was suggested by Furumura et al. (2011). Moreover, the maximum slip of about $10 \mathrm{~m}$ is suitable for the extended source area because the inclusion of a much larger slip in the Hyuga-Nada region induces an overestimate of the tsunami heights, as in the larger-earthquake scenario.

\section{Tsunami heights along the Pacific coastline of Shikoku region}

In Figure 8a, tsunami heights obtained from historical damage records from the 1707 Hoei tsunami event along the Pacific coast of the Shikoku region are plotted in pink, together with maximum-height tsunami profiles resulting from the larger- and smaller-earthquake scenarios, plotted in black and gray, respectively. As most of the real damage records lie between the maximum-height tsunami profiles resulting from the larger- and smaller-earthquake scenarios, the $K$-values for the larger- and smaller-earthquake 


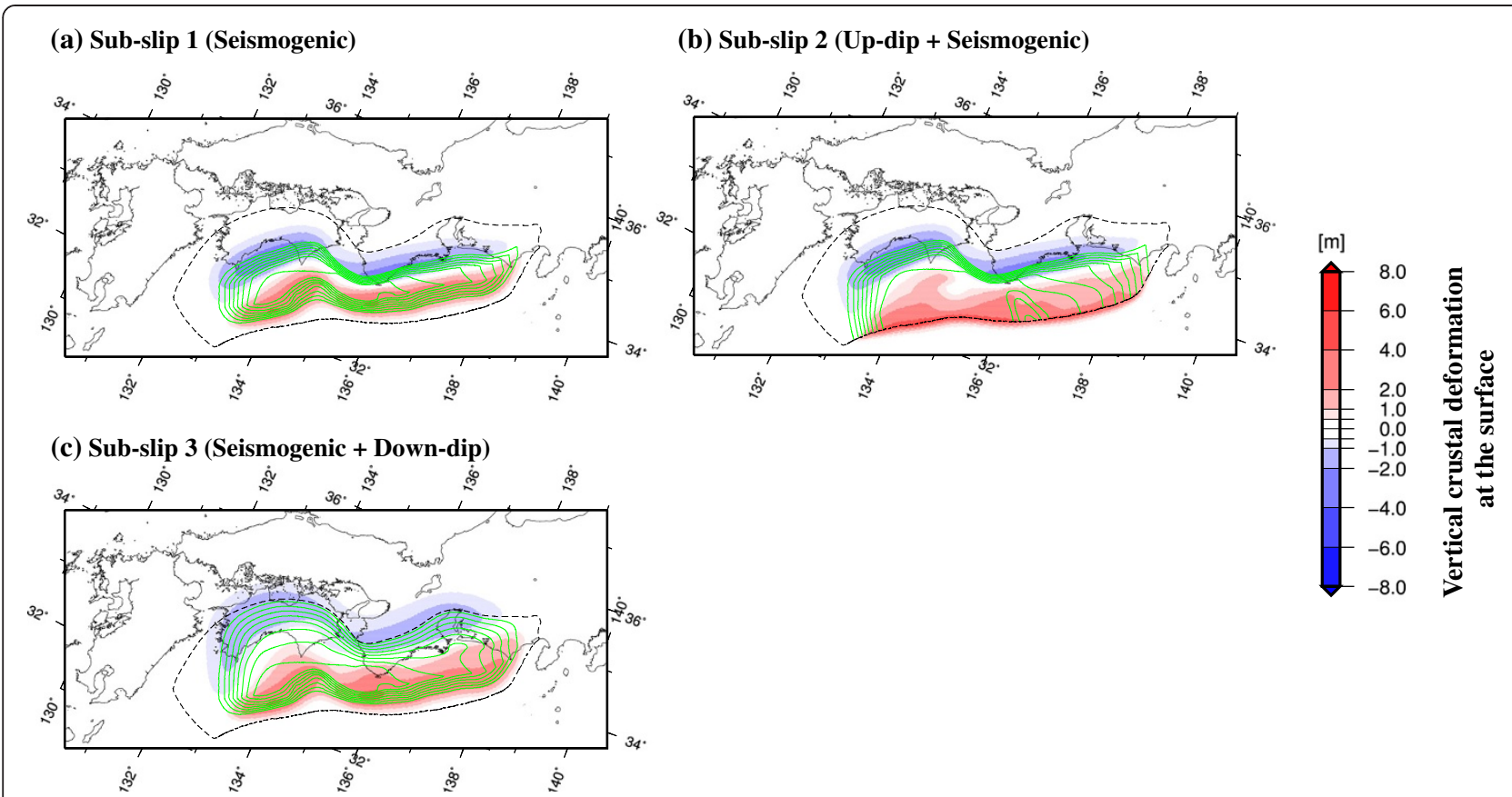

Figure 6 Slip distributions and resultant vertical deformations for the three sub-slip models of the larger-earthquake scenario. In each panel, the assumed slip distribution is represented by green contour lines with intervals of $2 \mathrm{~m}$; blue and red regions correspond to subsidence and uplift, respectively. As a reference, the region with slip of $>1 \mathrm{~m}$ in the larger-earthquake scenario is bounded by the broken black line: (a) sub-slip model 1 of the larger-earthquake scenario, (b) sub-slip model 2 of the larger-earthquake scenario, and (c) sub-slip model 3 of the larger-earthquake scenario.

scenarios are far from 1 , i.e., they are 0.74 and 1.48 , respectively, as listed in Table 1. However, the tsunamiheight profiles of sub-slip models 1,2 , and 3, extracted from the larger-earthquake scenario, are scattered widely over Tosa Bay and southeastern Shikoku, near the Kii Channel (Figure 8b). Pacific coastal tsunami heights are strongly affected by whether the nearest segment ruptures. Moreover, if the nearest segment does rupture, the large slip at the up-dip end might cause the tsunami height to be greater at the coast than at the seismogenic zone (see the difference between red and blue lines in Figure $8 \mathrm{~b}$ ). Among the three tsunami-height profiles in Figure 8b, the

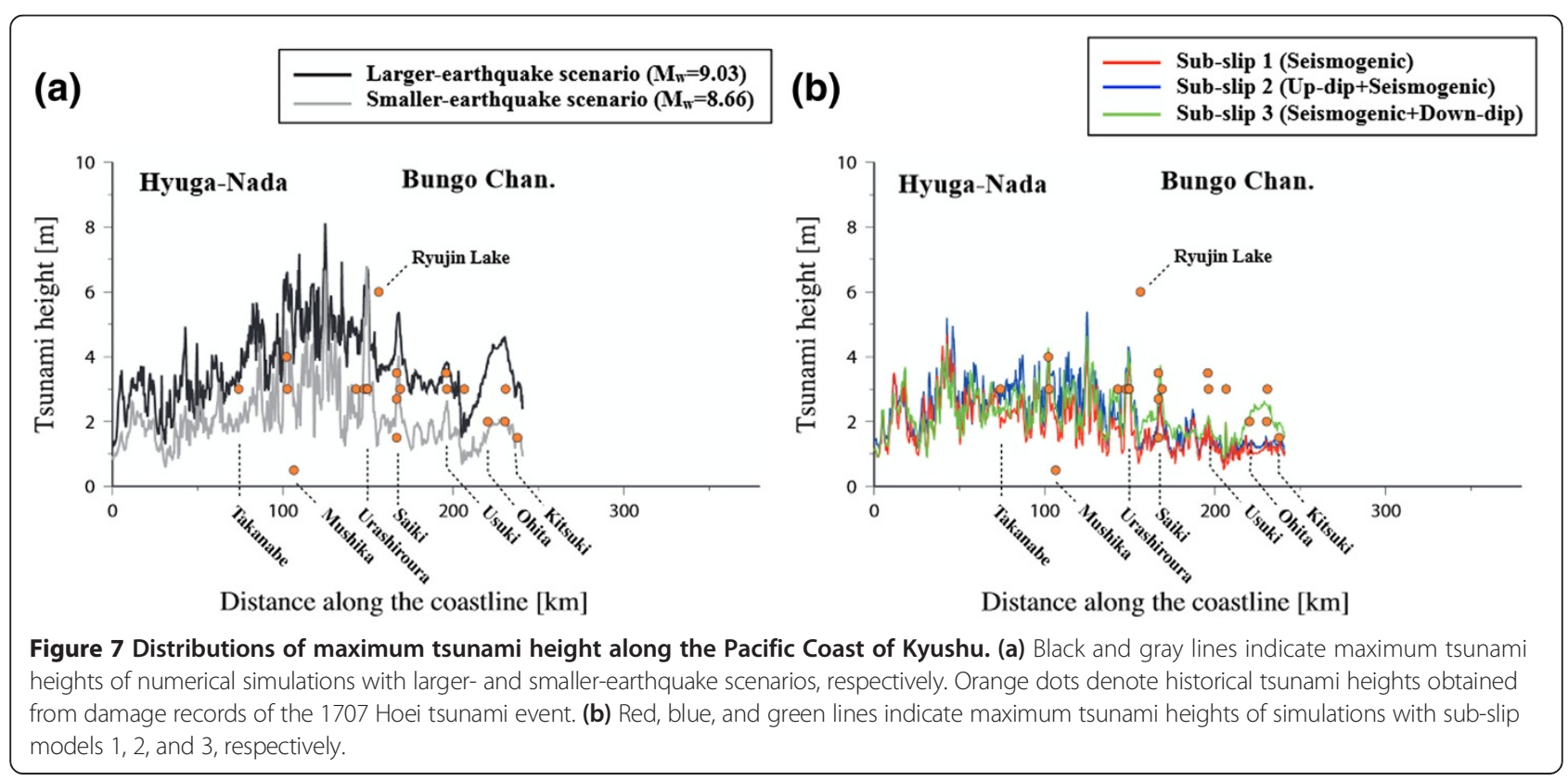


Table 1 Regional $K$ and $\boldsymbol{K}$ values for five earthquake scenarios

\begin{tabular}{|c|c|c|c|c|c|c|c|c|c|c|}
\hline \multirow[b]{2}{*}{ Scenario } & \multicolumn{2}{|c|}{ Kyushu (20) } & \multicolumn{2}{|c|}{ Shikoku (73) } & \multicolumn{2}{|c|}{ Kinki (29) } & \multicolumn{2}{|c|}{ Tokai (7) } & \multicolumn{2}{|c|}{ Seto (15) } \\
\hline & $K$ & $\kappa$ & $K$ & $\kappa$ & $K$ & $\kappa$ & $K$ & $\kappa$ & $K$ & $\kappa$ \\
\hline Large & 0.59 & 1.73 & 0.74 & 1.78 & 0.93 & 1.49 & 1.48 & 1.78 & 1.18 & 1.50 \\
\hline Small & 0.99 & 1.91 & 1.48 & 1.83 & 2.02 & 1.44 & 3.00 & 1.66 & 1.96 & 1.48 \\
\hline Sub 1 & 1.39 & 1.85 & 0.83 & 1.59 & 0.66 & 1.47 & 1.26 & 1.87 & 2.34 & 1.67 \\
\hline Sub 2 & 1.22 & 1.89 & 0.72 & 1.70 & 0.69 & 1.42 & 1.16 & 1.79 & 2.31 & 1.70 \\
\hline Sub 3 & 1.01 & 1.74 & 0.98 & 1.61 & 0.90 & 1.47 & 1.93 & 1.56 & 1.37 & 1.46 \\
\hline
\end{tabular}

$K$ indicates the geometric mean of the ratio of observed to simulated tsunami height and $K$ shows the uncertainty in $K$. Numerals in the top row indicate the number of damaged sites used for the evaluation of regional $K$ and $K$.

profile resulting from sub-slip model 3, which was assumed to have slip only on the seismogenic and down-dip extensions, is highly consistent with historical records of damage and for which the resultant $K$-value is 0.98 , as shown in Table 1 . The removal of slip on the down-dip extension from sub-slip model 3 leads to a smaller $K$ value, as with sub-slip model $1(K=0.83)$. Because the smaller $K$-value means a higher profile than the damage records, it might appear strange that the contraction of the source area from sub-slip 3 to sub-slip 1 makes the tsunami profile higher. This is mainly because the slip on the down-dip extension reduces both the Pacific coastal subsidence and the resultant tsunami heights along the Pacific coast. The inclusion of the up-dip slip in sub-slip model 2 makes the tsunami heights much greater and the $K$-value becomes smaller $(K=0.72)$.

\section{Tsunami heights along the Pacific coastline of} Kinki region

In Figure 9a, tsunami heights obtained from historical damage records from the 1707 Hoei tsunami event along the Pacific coast of the Kinki region are plotted in green, together with maximum-height tsunami profiles resulting from the larger- and smaller-earthquake scenarios, plotted in black and gray, respectively. As indicated in Figure 9a, historical damage records for the Kinki region fit the profile resulting from the larger-earthquake scenario with a $K$-value of 0.93 (see Table 1), unlike the Kyushu and Shikoku regions shown in Figures $7 \mathrm{a}$ and $8 \mathrm{a}$, respectively. However, there are several discrepancies to the west of Tanabe and east of Owase. Furthermore, tsunami-height predictions resulting from the smaller-earthquake scenario are generally smaller than the historical tsunami heights $(K=2.02)$. This indicates that slip on segments B and C, with a maximum of about $10 \mathrm{~m}$ (see green contours in Figure 3b), cannot explain the historical damage records for the Pacific coast in the Kinki region.

From the predictions of sub-slip models for the largerearthquake scenario (Figure 9b), it can be observed that sub-slip model 3, which was assumed to have slip only on the seismogenic and down-dip extensions, resembles the large-tsunami scenario in Figure 9a, and $K$-value for the

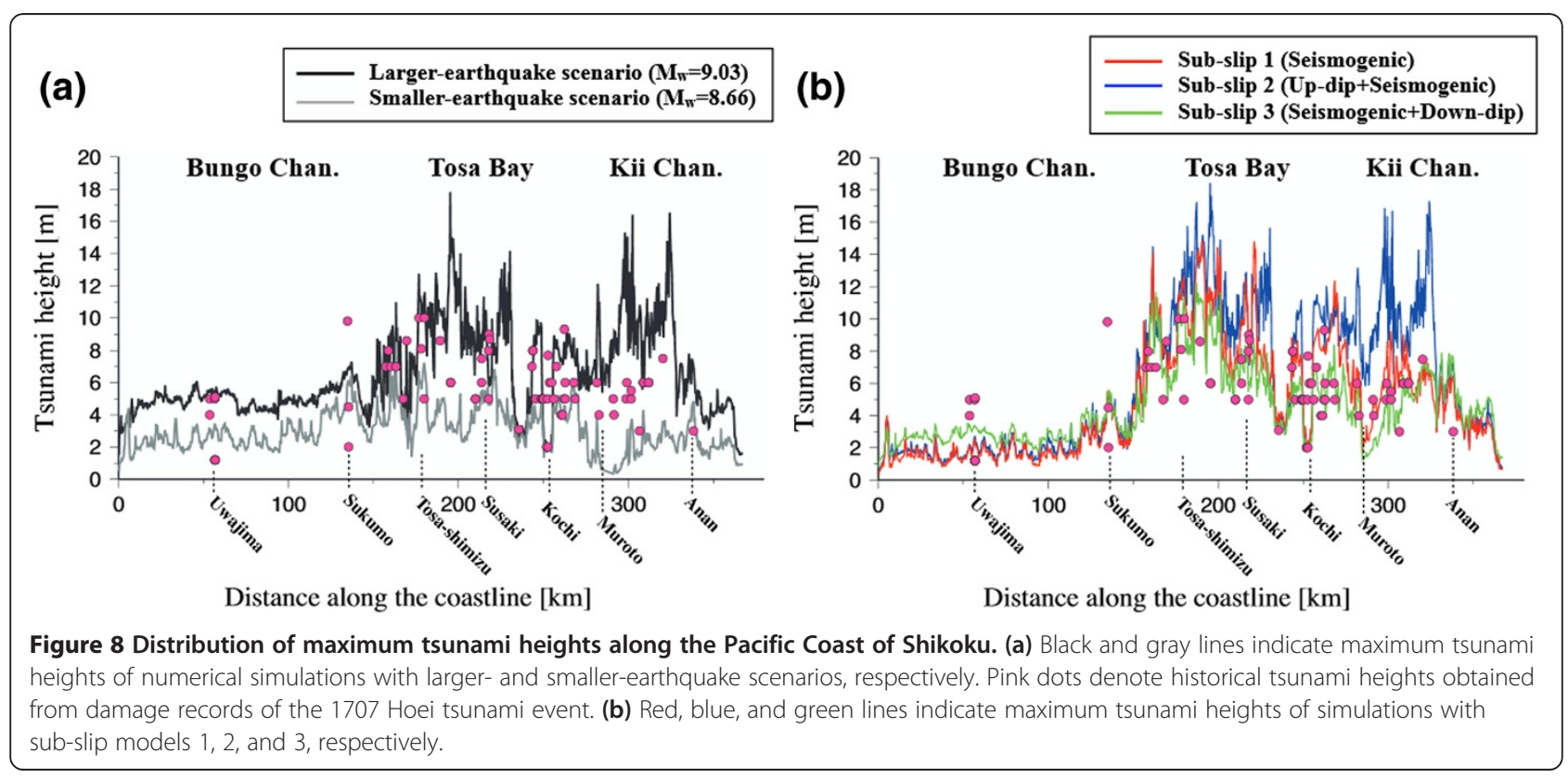




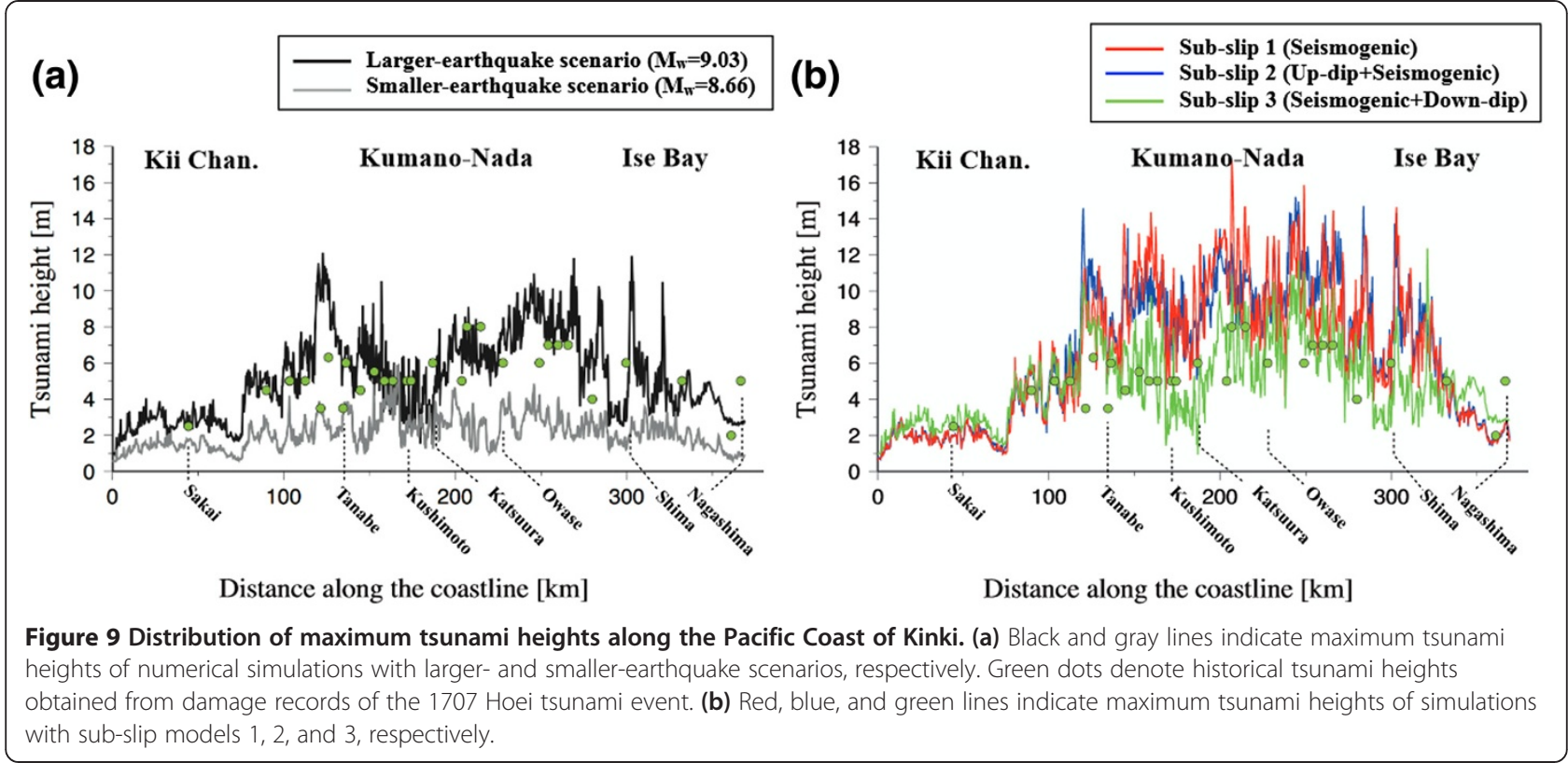

sub-slip model 3 is 0.90 . Conversely, sub-slip models 1 and 2 indicate considerable mutual correlation with poor $K$-values $(0.66$ and 0.69 , as shown in Table 1$)$. Small $K$ values for these two models indicate that the up-dip extensions of segments $B$ and $C$ have little effect on damage done to sites throughout the Kinki region. Thus, the Pacific coastal tsunami damage sustained by the Kinki region is compatible with large slip to the up-dip end on the segment off the Kii Peninsula, as suggested by Sakaguchi et al. (2011). Moreover, it is interesting that sub-slip model 1 , which included rupture of the seismogenic zone only, predicted greater tsunami heights than sub-slip model 3, which included the seismogenic and down-dip extensions. This feature is similar to the Pacific coast of Shikoku region. As shown in Figure 6, slip on the usual seismogenic zone causes subsidence of up to several meters along the Pacific coastline of Shikoku and Kinki regions, while inclusion of the down-dip extension makes this coastal subsidence shift landward. Because of this shift, crustal vertical deformation decreases considerably along the coastline. This explains why increasing the source area goes hand-in-hand with predictions of decreasing tsunami height.

\section{Tsunami heights along the Pacific coastline of Tokai region}

In Figure 10a, tsunami heights obtained from historical damage records from the 1707 Hoei tsunami event along the Pacific coast of Tokai region are plotted in blue, together with maximum-height tsunami profiles resulting from the larger- and smaller-earthquake scenarios, plotted in black and gray, respectively. As shown in Figure 10a, many historical damage records exceed the larger-earthquake profile.
Hence, the $K$-value for the larger-earthquake scenario becomes $>1(K=1.48)$. Whereas, as shown in Figure 10b, the profiles for sub-slip models 1 and 2 overtake the largerearthquake profile around Shirasuka. This is because the slip on the down-dip extension compensates for the coastal subsidence due to slip on the seismogenic zone, as explained in the previous section, that is, sub-slip model 3 (green profile in Figure 10b) predicted far smaller tsunami heights than sub-slip models 1 and 2 (red and blue lines in Figure 10b, respectively). Further to the east, tsunami heights predicted by the sub-slip models were much smaller than predicted by the larger-earthquake scenario because steep subduction in Suruga Bay and the assumed filter for the extraction of subslips greatly reduced slip amounts in the sub-slip models. The $K$-values for sub-slip models 1 and 2 are 1.26 and 1.16, respectively, which are better than that for the largerearthquake scenario $(K=1.48)$. Although the degree of fitness between the observed and calculated values for all scenarios appears poor in Figure 10a,b, the smaller $K_{i}$-values around Shirasuka and larger $K_{i}$-values at the east and west of Shimizu might cancel out when evaluating the $K$-values for sub-slip models 1 and 2.

Overall, Pacific coastal tsunami heights, predicted by the smaller-earthquake scenario, are systematically smaller than historical tsunami heights of the 1707 Hoei earthquake and tsunami events, except in Kyushu, whereas those predicted by the larger-earthquake scenario are more consistent than the smaller-earthquake scenario with historical tsunami heights from Shikoku to Tokai regions. Nonetheless, even for tsunami heights predicted by the larger-earthquake scenario, there are several large discrepancies between the simulated and historical tsunami heights for some sites. In particular, along Tosa Bay in the 


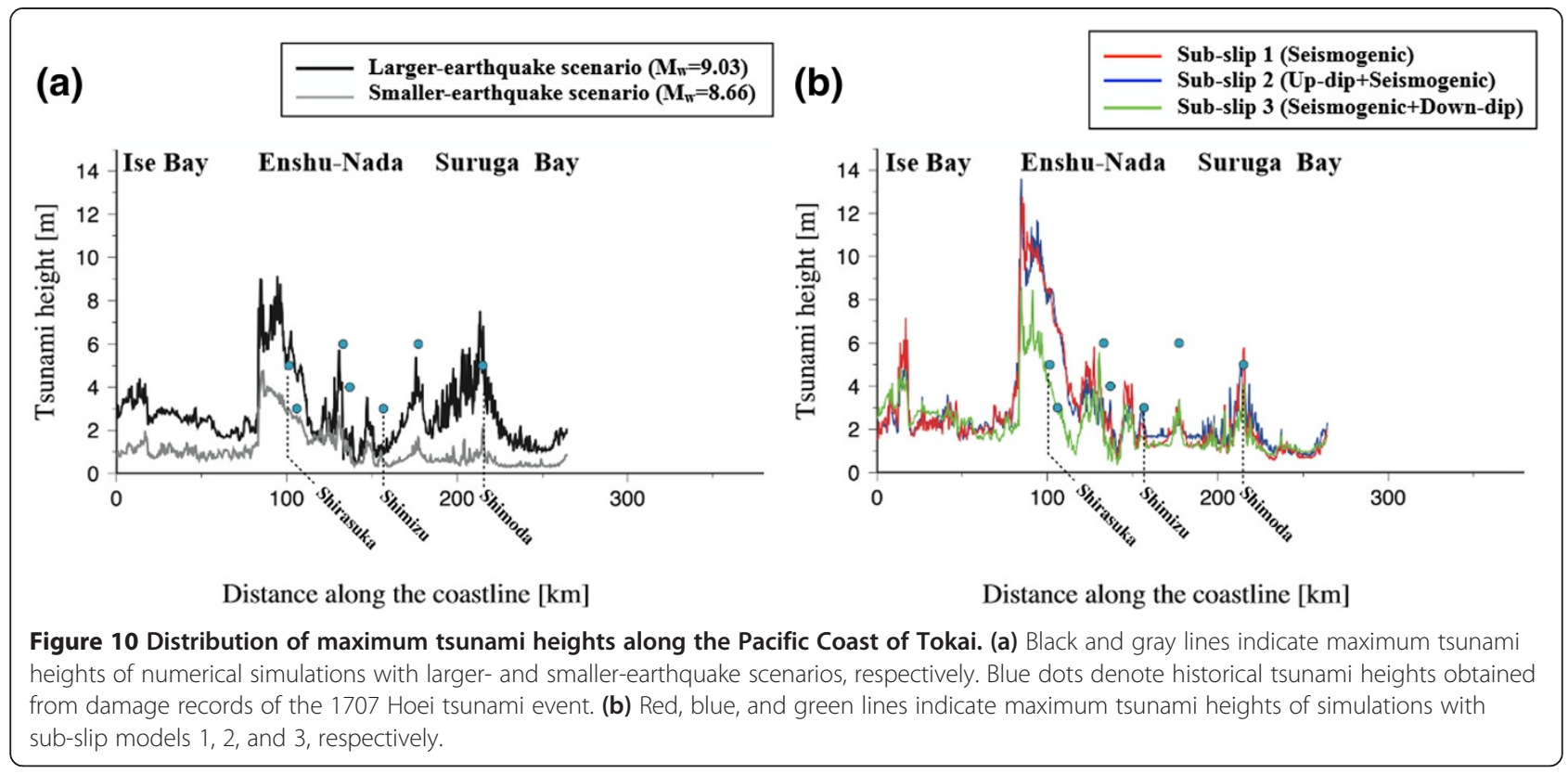

central Shikoku region, the eastern coastline of Shikoku, and the southwestern part of Kii Peninsula, tsunami heights are predicted to increase sharply, whereas historical heights at these locations do not. Hence, predicted profiles are often locally overestimated by several times compared with historical ones (Figures 8a and 9a). However, the results explained in above sub-sections associated with the Pacific coastal tsunamis at Shikoku and Kinki regions show that such discrepancies are caused mainly by large slip near the up-dip ends of segments A and B. Moreover, predictions made without large slip at these up-dip ends are more consistent with the tsunami heights obtained from historical damage records along the Pacific coast of Shikoku.

\section{Tsunami height in the Seto Inland Sea region}

As shown in Figure 2, not only the Pacific coastlines extending from the Kyushu to Tokai regions but also the Seto Inland Sea region were damaged by tsunamis higher than a few meters during the 1707 Hoei earthquake and tsunami events. However, damage records for the Seto Inland Sea region have not yet been taken into account in the comparisons of tsunami heights predicted by the possible scenarios. Here, in addition to the Pacific coastal tsunami heights, we treat damage records in the Seto Inland Sea as another constraint of historical earthquake size. A comparison was made for the simulated and historical tsunami heights for the Seto Inland Sea region, including 15 damaged sites localized from west to east along the Seto Inland Sea coast (Figure 11). The locations of the observation sites are shown in Figure 11a, and in Figure 11b, the simulated tsunami heights due to the larger- and smallerearthquake scenarios are plotted against the locations of the damaged sites. Although tsunami heights predicted by the smaller-earthquake scenario are smaller than those obtained from historical damage records, the largerearthquake scenario predicts a profile of tsunami heights consistent with that obtained from historical damage records, except for Takamatsu, Kanzaki, and Ako, which are located in the central part of the Seto Inland Sea region. Thus, although the $K$-value for the larger-earthquake scenario is 1.18 (see Table 1 ), the $K$-value would be close to 1 were the stations near the central Seto Inland Sea removed.

For Pacific coastal tsunami heights, we confirmed the rupture effect of the nearest segment to be dominant in reproducing tsunami heights comparable with historical damage records. Furthermore, we also examined the critical factor for generating large tsunami heights in the Seto Inland Sea. Figure 11c shows the tsunami-height profiles obtained using the sub-slip models for the larger-earthquake scenario. From the results of sub-slip models 1 and 2 (red and blue lines in Figure 11c, respectively), the up-dip extension of the seismogenic zone can be seen to have almost no effect on tsunami height in the Seto Inland Sea, and the total tsunami heights are the same as those of the smallerearthquake scenario. The $K$-values for sub-slip models 1,2 , and the smaller-earthquake scenario are poor with values of 2.34, 2.31, and 1.96, respectively (Table 1). Conversely, the down-dip extension shifts the subsidence associated with the down-dip edge of the slip landward (as mentioned in the sub-section associated with the Pacific coastal tsunami in Shikoku region) and raises tsunami heights up to about $1 \mathrm{~m}$ for the Seto Inland Sea (green line Figure 11c). The resultant profile is almost the same as that of the largerearthquake scenario, except for the western edge of the 


\section{(a)}
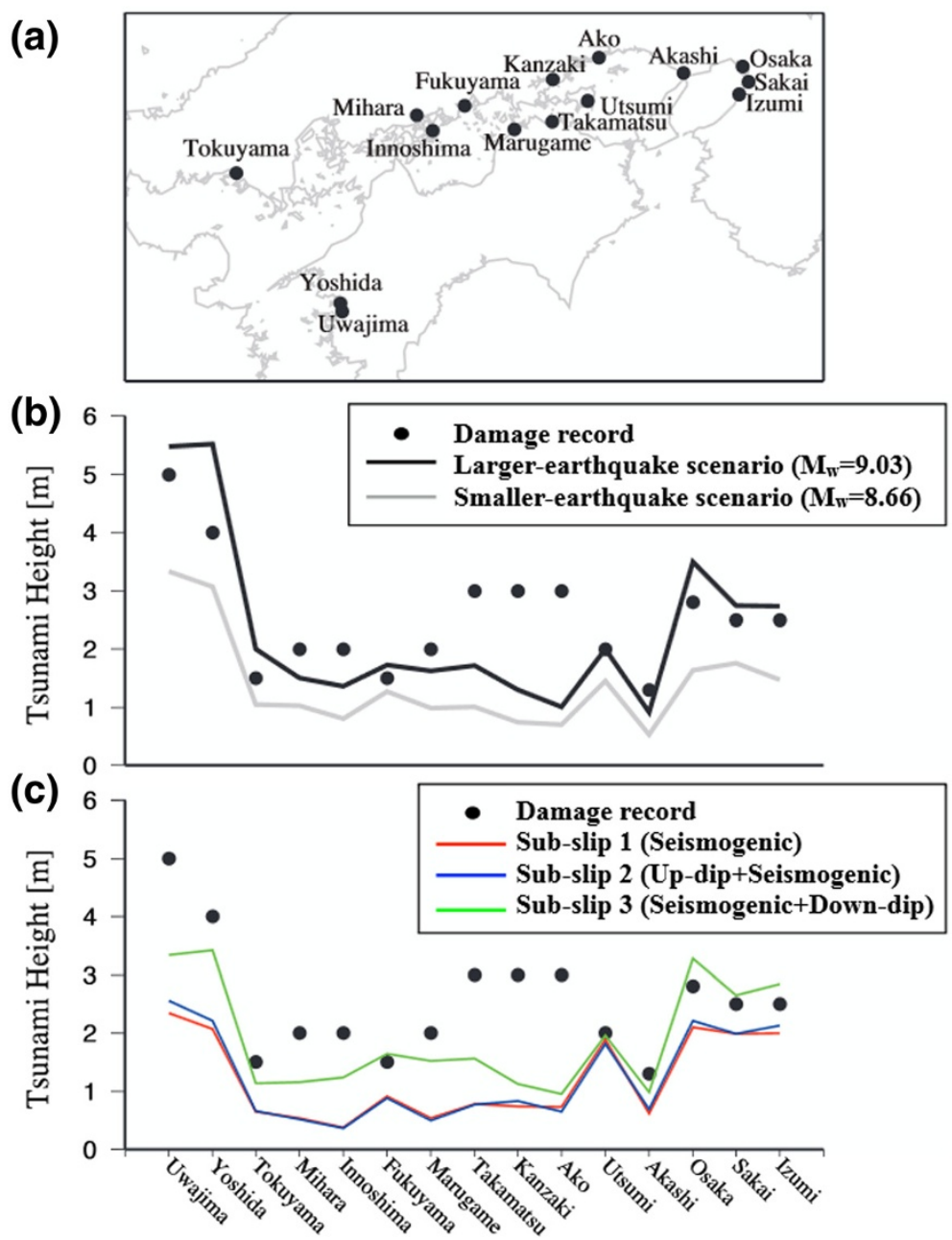

Figure 11 Comparison between real damage records for the 1707 Hoei earthquake and tsunami events and simulated tsunami heights for the Seto Inland Sea region. (a) Distribution of damaged sites over the Seto Inland Sea region. (b) Comparison of historical and predicted tsunami heights based on the larger- and smaller-earthquake scenarios. (c) Comparison with predicted tsunami heights based on sub-slip models of the larger-earthquake scenario.

Seto Inland Sea. The $K$-value for sub-slip model 3 is improved to be 1.37 , and this value is a little larger than that for larger-earthquake scenario.

Based on all the $K$-values presented in Table 1, we drew Figure 12 in order to simplify the identification of the most appropriate scenario for the historical tsunami heights of the 1707 Hoei event. From the scatter of circles above each scenario in Figure 12, the larger earthquake and sub-slip model 3 appear more appropriate than the other three scenarios, although they do have poor $K$ values for the Tokai region. Throughout this paper, we have considered the effect of crustal deformation on inland tsunami height and have discussed the importance of slip on the down-dip extension when explaining inland tsunamis. However, because there is no evidence to suggest sudden subsidence of the Seto Inland Sea coast in 1707, this is only one possible explanation for the 1707
Hoei inland tsunami event. Based on in emerged sessile assemblages along the Pacific coast, Shishikura et al. (2011) found evidence of repeated uplift events. Because these events coincided with large Nankai Trough earthquake events, it is clear that these earthquakes uplift the Pacific coastline. Therefore, in order to narrow down possible causes of the 1707 Hoei inland tsunami event and potentially shed more light on its origins, the Pacific and Seto Inland Sea coastlines should be explored for traces of coseismic crustal deformation.

Other factors that might affect inland tsunami height include ocean currents or earth tides. For tsunamis in the Seto Inland Sea, Miyamoto et al. (2006) discussed the possibility of amplification of tsunami heights by earth tide. Owing to the narrow straits located at the western and eastern edges of the Seto Inland Sea, earth tides cause sharp differences in water level (with a maximum gap of 


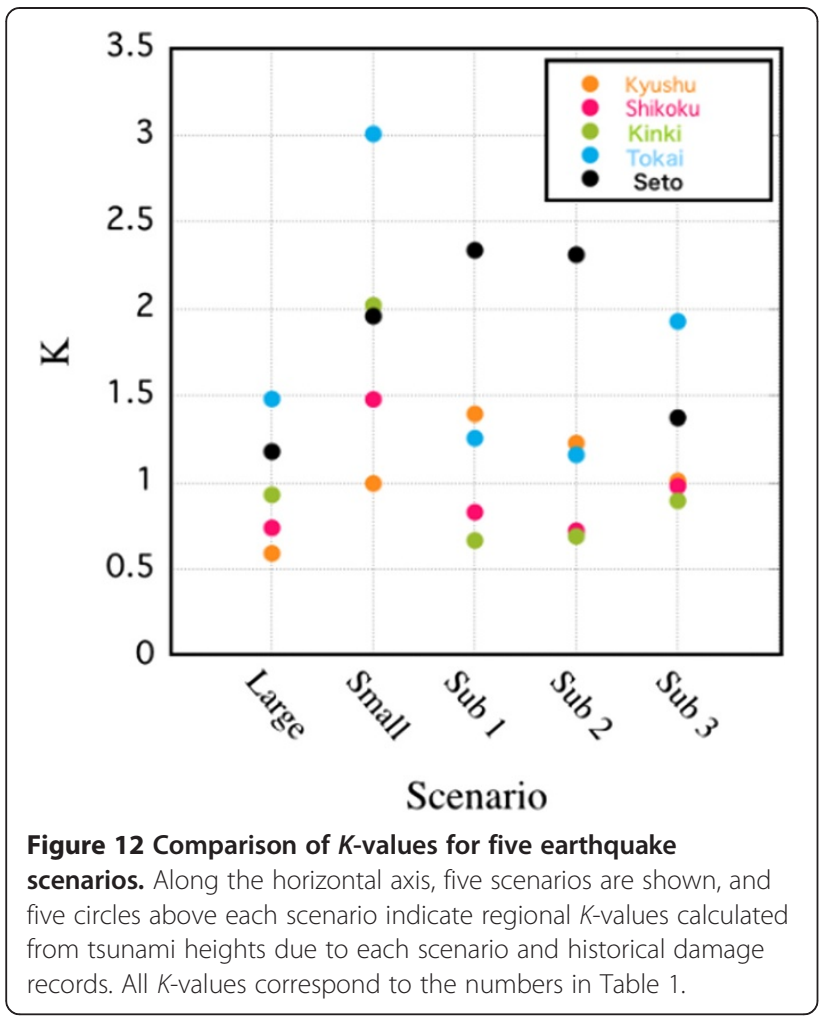

several meters) between the Seto Inland Sea and the open sea, resulting in local changes of flow velocities of ocean currents through these straits. As the Nankai Trough earthquake tsunamis surge through the Kii or Bungo Channels, such changes in flow velocities of ocean currents might affect their velocities or heights. Increases in tsunami heights due to tidal coupling were estimated to be about $0.5 \mathrm{~m}$ at most by Miyamoto et al. (2006), and through calculation of tsunami flows in the Seto Inland Sea - assuming an initial tidal gap of a few meters between the inland and open seas - they concluded that tidal effects were practically negligible. However, they adopted a minimum spatial grid size of $450 \mathrm{~m}$ for the simulation of the Seto Inland Sea region, which is about ten times larger than that adopted in this paper. Such a coarse grid size cannot resolve the complex bathymetry of the Seto Inland Sea and might result in large underestimations of tsunami heights. Hence, the coupling of tsunamis, tidal effects, and ocean currents should be reexamined using finer grid sizes for better and more localized understanding of the historical records of severe damage to the central part of the Seto Inland Sea region caused by the 1707 Hoei tsunami event. Such work would improve the assessment of the potential for disaster from future tsunamis in the Seto Inland Sea.

We believe that the collection of various earthquake scenarios, consistent with historical earthquakes, is important for preparing against the next Nankai Trough earthquake. Of the historical Nankai Trough earthquakes, the 1707 Hoei earthquake is the largest that has many available descriptions in old documents. Therefore, by making full use of the historical data associated with the Hoei earthquake, we can estimate the characteristics of larger Nankai Trough earthquakes.

Therefore, the available damage records from the Pacific and Seto Inland Sea were used to explore the source scenarios for the 1707 Hoei earthquake and tsunami event. As a reference scenario of the 1707 event, we first selected the simulation-based $\mathrm{M}_{\mathrm{w}}$ 9-class earthquake of Hyodo and Hori (2013), which has a similar source area to the maximum models of Cabinet Office (2012); although the maximum slip at the up-dip end is less than half. Then, by decomposing this $\mathrm{M}_{\mathrm{w}}$ 9-class scenario into sub-slips, we calculated the various resultant tsunami profiles and determined the most appropriate scenario among them to represent the 1707 Hoei tsunami damages in the Pacific and Seto Inland Sea coasts. By excluding the large slips both near the up-dip end off Shikoku and the southward extension of large slip beyond $32^{\circ} \mathrm{N}$ from the $\mathrm{M}_{\mathrm{w}}$-class scenario, the consistency with the 1707 Hoei tsunami heights was improved considerably from the original $\mathrm{M}_{\mathrm{w}}$ 9-class scenario.

\section{Conclusions}

As a first step in validating the many Nankai Trough earthquake scenarios available, we examined the effects of both lateral and vertical expansions of the segments on the maximum tsunami heights along the Pacific and Seto Inland Sea coasts for the proposed $\mathrm{M}_{\mathrm{w}}$ 9-class Nankai Trough earthquake scenario (Hyodo and Hori 2013). Comparing the $\mathrm{M}_{\mathrm{w}}$ 9-class Nankai Trough earthquake scenario with the historical 1707 Hoei earthquake and tsunami events, we found the following similarities and differences between the simulated and historical events:

- The westward extension of rupture segments with about 10-m slip is indispensable for explaining the historical damage along the Pacific coastal region of Kyushu, which is similar to the findings of Furumura et al. (2011).

- The up-dip extension of large slip on segments off Shikoku Island predicts tsunamis much larger than the 1707 Hoei tsunami, resulting in far more damage to regions along the Pacific coast, such as Tosa Bay, southeastern Shikoku Island, and the southwestern Kii areas. Conversely, the assumption of source areas with usual up-dip limits (approximately 10-km depth) of large slip provides coastal profiles of maximum tsunami heights that are more consistent.

- Owing to the associated crustal vertical deformation, the down-dip extension of large slip on segments beneath Shikoku Island induces tsunamis higher 
than a few meters in the Seto Inland Sea region. These tsunami heights are comparable with those observed during the 1707 Hoei tsunami event, except for in the central part of the Seto Inland Sea where tsunami heights higher than in the surrounding areas were observed.

- For the Pacific coastal tsunamis affecting the Shikoku to Kii regions, a down-dip extension of large slip is necessary, down to about $30 \mathrm{~km}$ or deeper. In other words, a shallower down-dip limit causes subsidence of the coastline from the Shikoku to Kii regions, and maximum tsunami heights become significantly larger than the 1707 Hoei tsunami.

\section{Competing interests}

The authors declare that they have no competing interests.

\section{Authors' contributions}

$\mathrm{MH}$ processed simulated tsunami heights for the comparison with historical damages, and drafted the manuscript. TH participated in the design of the study and drafted the manuscript. KA prepared the bathymetry data for the tsunami simulation, and executed tsunami simulations on $\mathrm{K}$ computer. TB modified the tsunami simulation code for this study. All authors read and approved the final manuscript.

\section{Acknowledgements}

We thank the editor and anonymous reviewer for their constructive comments for improving the manuscript. This research was implemented in the Strategic Programs for Innovative Research, Field 3, and part of the results were obtained using the $\mathrm{K}$ computer at the RIKEN Advanced Institute for Computational Science (Proposal number hp120278). We thank Dr. Ritsuko Matsu'ura for providing us with important information on tsunami damage records of the Seto Inland Sea region. We thank Dr. Kentaro Imai for his cooperation and for providing us with the maximum tsunami-height data compiled from existing studies (Hatori 1974, 1985; Murakami et al. 1996).

\section{Author details}

'Research and Development Center for Earthquake and Tsunami (CEAT), Japan Agency for Marine-Earth Science and Technology (JAMSTEC), 3173-25 Showa-machi, Kanagawa-ku, Yokohama, Kanagawa 236-0001, Japan. ${ }^{2}$ Center for Earth Information Science and Technology (CEIST), Japan Agency for Marine-Earth Science and Technology (JAMSTEC), 3173-25

Minatojima-minami-machi, Chuo-ku, Kobe, Hyogo 650-0047, Japan.

Received: 10 March 2014 Accepted: 17 September 2014

Published: 25 September 2014

\section{References}

Aida I (1978) Reliability of a tsunami source model derived from fault parameters. J Phys Earth 23:381-390

Baba T, Takahashi N, Kaneda Y, Inazawa Y, Kikkajin M (2014) Tsunami inundation modeling of the 2011 Tohoku earthquake using three-dimensional building data for Sendai, Miyagi Prefecture, Japan. In: Kontar YA, Fandino VS, Takahashi T (eds) Tsunami events and lessons learned; ecological and social significance, vol 35. Springer, Dordrecht Heidelberg New York London, pp 89-98

Cabinet Office (2012) Anticipated damages due to the Nankai Trough mega-thrust earthquake (second report), http://uww.bousai.go.jp/jishin/nankai/taisaku/pdf/ 1_1.pdf, Accessed Feb. 26, 2014

Central Disaster Prevention Council (2003) Report associated with Tonankai and Nankai earthquakes. http://www.bousai.go.jp/kaigirep/chuobou/9/pdf/ zuhyou 2-2.pdf, Accessed Mar. 6, 2014

Fujiwara T, Kodaira S, No T, Kaiho Y, Takahashi N, Kaneda Y (2011) The 2011 Tohoku-Oki earthquake: displacement reaching the trench axis. Science 334:1240, http://dx.doi.org/10.1126/science.1211554.

Fukao Y (1979) Tsunami earthquakes and subduction processes near deep-sea trenches. J Geophys Res 84:2303-2314
Furumura T, Imai K, Maeda T (2011) A revised tsunami source model for the 1707 Hoei earthquake and simulation of tsunami inundation of Ryujin Lake, Kyushu, Japan. J Geophys Res 116:1-17

Hatori T (1974) Sources of large tsunamis in southwest Japan. J Seismol Soc Jpn 27:10-24

Hatori T (1985) Field investigation of historical tsunamis along the east coast of Kyushu, West Japan. Bull Earthquake Res Inst Univ Tokyo 60:439-459

Hatori T (1988) Tsunami behaviors in the Seto Inland Sea and Bungo Channel caused by the Nankaido earthquakes in 1707, 1854 and 1946. J Seismol Soc Jpn 41:215-221

Hori T (2006) Mechanisms of separation of rupture area and variation in time interval and size of great earthquakes along the Nankai Trough, southwest Japan. J Earth Simulator 5:8-19

Hori T, Kato N, Hirahara K, Baba T, Kaneda Y (2004) A numerical simulation of earthquake cycles along the Nankai Trough in southwest Japan: lateral variation in frictional property due to slab geometry controls the nucleation position. Earth Planet Sci Lett 228:215-226

Hyodo M, Hori T (2013) Re-examination of possible great interplate earthquake scenarios in the Nankai Trough, southwest Japan, based on recent findings and numerical simulations. Tectonophysics 600:175-186

Ishibashi K (2004) Status of historical seismology in Japan. Ann Geophys 47:339-368

Kitahara I, Matsu'ura R, Kimura R (eds) (2012) Japan historical disaster dictionary. Yoshikawakobun-kan, Tokyo

Miyamoto D, Murakami H, Kozuki Y, Kubo T (2006) The effect of earth tide, incident angle and periods of tsunamis on the behavior of tsunamis in the Seto Inland Sea (in Japanese). Proc Coastal Eng JSCE 53:261-265

Murakami H, Shimoda T, Itoh S, Yamamoto N, Ishizuka J (1996) Reexamination of the heights of the 1606, 1707 and 1854 Nankai tsunamis along the coast of Shikoku Island. J Jpn Soc Nat Disaster Sci 15(1):39-52

Namegaya Y, Maemoku H, Shishikura M, Echigo T, Nagai A (2011) Factors causing scattered boulders located around Hashigui-iwa, the southernmost of Kii Peninsula, Japan. Japan Geoscience Union Meeting 2011. Makuhari Messe International Conference Hall, Chiba, 22-27 May 2011

Park J-O, Kodaira S (2012) Seismic reflection and bathymetric evidences for the Nankai earthquake rupture across a stable segment-boundary. Earth Planets Space 64:299-303, doi:10.5047/eps.2011.10.006

Sakaguchi A, Chester F, Curewitz D, Fabbri O, Goldsby D, Kimura G, Li CF, Masaki Y, Screaton EJ, Tsutsumi A, Ujiie K, Yamaguchi A (2011) Seismic slip propagation to the up-dip end of plate boundary subduction interface faults: vitrinite reflectance geothermometry on Integrated Ocean Drilling Program NanTroSEIZE cores. Geology 39:395-398

Shishikura M, Maemoku H, Echigo T, Namegaya Y, Nagai A (2011) History of multi segment earthquake along the Nankai Trough, deduced from tsunami boulders and emerged sessile assemblage. Japan Geoscience Union Meeting 2011. Makuhari Messe international conference hall, Chiba, 22-27 May 2011

\section{doi:10.1186/1880-5981-66-123}

Cite this article as: Hyodo et al.: The possibility of deeper or shallower extent of the source area of Nankai Trough earthquakes based on the 1707 Hoei tsunami heights along the Pacific and Seto Inland Sea coasts, southwest Japan. Earth, Planets and Space 2014 66:123.

\section{Submit your manuscript to a SpringerOpen ${ }^{\circ}$ journal and benefit from:}

- Convenient online submission

$\checkmark$ Rigorous peer review

- Immediate publication on acceptance

- Open access: articles freely available online

- High visibility within the field

- Retaining the copyright to your article

Submit your next manuscript at $\boldsymbol{~ s p r i n g e r o p e n . c o m ~}$ 